\title{
CONSTRUÇÃO DE SABERES SOBRE O CORPO: O FAZER FALAR DE UM SABER MÉDICO
}

\author{
CONSTRUCTION OF KNOWLEDGE ABOUT THE BODY: DOING TALK ABOUT A MEDICAL \\ KNOWLEDGE
}

\author{
Renato Azambuja* \\ Nadia Geisa Silveira de Souza**
}

\begin{abstract}
RESUMO
Verdades médicas são entendidas como saberes constituídos historicamente em suas complexidades e heterogeneidades. Para a biomedicina, as práticas discursivas tendem a levar efeitos em que os indivíduos se subjetivam enquanto corpos estruturados em órgãos, independentemente do contexto onde se processam as relações do seu viver. Trazemos uma visão que integra mente e corpo na compreensão da enfermidade, a partir de um saber médico historicamente sujeitado, a Homeopatia, sobre os processos de adoecimento e pela possibilidade de uma prática em saúde transformadora de si. Para tanto, apresentamos, inicialmente, um olhar histórico na configuração do que veio a se tornar a biomedicina, articulada aos atravessamentos de poder/saber que permeavam a sociedade ocidental europeia entre os séculos XVIII e XIX. Coincidentemente, o mesmo período histórico testemunhou o nascimento de outra prática médica, a Homeopatia, que, apresentando outra compreensão das relações entre corpo e mente, tornou-se sujeitada ante a então nova verdade anatômica sobre o corpo.
\end{abstract}

PALAVRAS-CHAVE: biomedicina; biopoder; homeopatia; cuidado de si.

\begin{abstract}
Medical truths are understood as knowledges historically constituted in their complexities and heterogeneities that constituted them. For the biomedicine, discursive practices tend to lead to effects in which individuals subjectify themselves as organ-structured bodies, regardless of the context in which their living relationships are processed. We bring a vision that integrates mind and body in the understanding of the disease, from a historically subjected medical knowledge, Homeopathy, about the processes of illness and the possibility of a practice in self-transforming health. Therefore, we initially present a historical look at the configuration of what has become biomedicine, articulated with the crossings of power/knowledge that permeated Western European society between the 18th and 19th centuries. Coincidentally, the same historical period witnessed the birth of another medical practice, Homeopathy, which, presenting another understanding of the relationship between body and mind, became subject to the then new anatomical truth about the body.

\footnotetext{
* Doutorando no PPG de Educação em ciências pela UFRGS e mestre no PPG de Educação em ciência pela mesma instituição. Esse estudo vincula-se a dissertação "O corpo, a mente e o sujeito: será possível um cuidado de si em saúde que considere o modo existencial do paciente?" defendida em fevereiro de 2019 no PPG de Educação em Ciências: Química da vida e Saúde/ICBS/UFRGS. Email: renatodeazambuja@ gmail.com.

** Mestra em Ciências Biológicas (Bioquímica) pela Universidade Federal do Rio Grande do Sul e doutora em Ciências Biológicas (Bioquímica) pela mesma Universidade. E-mail: nadiagsouza@gmail.com.
}

Sapere aude - Belo Horizonte, v. 12 - n. 23, p. 128-147, Jan./Jun. 2021 - ISSN: 2177-6342 
KEY-WORDS: biomedicine; biopower; homeopathy; self care. INTRODUÇÃO

A biomedicina constitui um campo de saber no âmbito do cuidado com a saúde e com o corpo. As práticas discursivas da biomedicina tendem a levar efeitos em que os indivíduos se subjetivam enquanto corpos objetivos, estruturados em órgãos, existindo independentemente do contexto onde se processam as relações do viver com suas historicidades e que não dependem da incorporação dos processos psíquicos na própria compreensão do seu corpo. Para o saber biomédico, a relação sintoma-doença é mecânica e além de redutível, quase que exclusivamente, a objetividade do patológico e anormal sobre o organismo. Pretendemos fomentar uma discussão acerca de outra visão de corpo. Uma visão que integra o psiquismo e o corpo nos processos de compreensão da enfermidade como experiência existencial, a partir de um saber médico historicamente sujeitado: a Homeopatia.

Para tanto, apresentamos, inicialmente, um olhar histórico na configuração do que veio a se tornar a biomedicina, articulada aos atravessamentos de poder/saber que permeavam a sociedade ocidental europeia entre os séculos XVIII e XIX. Coincidentemente, o mesmo período histórico testemunhou o nascimento de outra prática médica, a Homeopatia, que, apresentando outra compreensão das relações entre corpo e mente, tornou-se sujeitada ante a então nova verdade anatômica sobre o corpo.

\section{OS SABERES MÉDICOS E SEUS EMBATES NOS SÉCULOS XVIII E XIX}

O século XVIII foi uma época de grandes transformações sociais, econômicas e políticas que moldaram os embates relativos às práticas e aos saberes médicos que vigoravam no período. Diante de um processo crescente de urbanização, da constituição dos Estados modernos europeus, do fomento ao intercâmbio comercial entre diversos países, da exploração de rotas comerciais nunca antes exploradas, de processos migratórios entre povos e da reformulação de todo um aparato legal e jurídico, a população e seus fenômenos biológicos - como a natalidade, morbidade, mortalidade e endemias - não escaparam de ser objeto de exame por meio da coleta de dados e intervenções para um novo modo de se organizar a vida. Entre várias modificações no modo de se governar e lidar com a vida, tornou-se necessária uma transformação no olhar direcionado ao corpo

Sapere aude - Belo Horizonte, v. 12 - n. 23, p. 128-147, Jan./Jun. 2021 - ISSN: 2177-6342 
e suas mazelas na constituição de um saber médico-terapêutico, visando o controle de epidemias e a medicalização das doenças populacionais que começavam a ser descritas por esse saber. $\mathrm{O}$ objetivo era estabelecer padrões de normalidades e estabelecer estratégias de normalização dos corpos, e a medicina seria uma estratégia fundamental nesse sentido.

As transformações do olhar médico sobre o corpo não se deram como simples evolução do método científico, mas como embates de modos de se observar o vivo e suas enfermidades. Travavam-se, à época, intensos debates, principalmente entre duas correntes doutrinárias na medicina ligadas ao Iluminismo, o vitalismo e o mecanicismo. O vitalismo defendia que o organismo não poderia ser considerado como a soma de seus órgãos relacionados por meio de sua estrutura material, mas que haveria um agente vital a manter a integridade do organismo e de suas funções, as leis da mecânica dos órgãos não poderiam explicar as manifestações do vivo. Já para os seguidores da corrente mecanicista o corpo seria uma estrutura física e material bem organizada, regulada de acordo com a filosofia cartesiana. Essas clássicas posições antagônicas oriundas das medicinas praticadas na Grécia antiga — os vitalistas de inspiração aristotélica por um lado e por outro os atomistas de Demócrito junto com os anatomistas de Galeno — poderiam ser vistas como referenciais históricos das diferenças entre os saberes médicos da homeopatia e da contemporânea biomedicina.

O debate, no final do século XVIII, mostrava-se complexo e heterogêneo, com nuances imprecisas nas demarcações desses campos de saber, pois alguns vitalistas contribuíram significativamente para, por exemplo, o conhecimento de embriogênese ou, como Bichat, para a produção dos discursos da anatomoclínica (CANGUILHEM, 2012). Ao mesmo tempo, médicos materialistas ancoravam suas práticas nos métodos da medicina classificatória (FOUCAULT, 2004), que se sustentava em saberes empíricos e que, à época, foi abandonada a favor dos saberes da recente e inovadora anatomoclínica. No entanto, veremos que, paradoxalmente, alguns conceitos daquela medicina classificatória serviram para gerar um diferente modo de percepção da doença e dos sintomas do corpo. Ao se considerar significante a sincronicidade empírica do conjunto de sintomas experimentados no viver a enfermidade, integrou-se, posteriormente, o vitalismo hahnemanniano para se conhecer o corpo. Para a homeopatia, a totalidade dos sintomas passa a ser a única forma de se conhecer a enfermidade, diferente da anatomoclínica, que olhava para a objetividade patológica da alteração dos tecidos.

Sapere aude - Belo Horizonte, v. 12 - n. 23, p. 128-147, Jan./Jun. 2021 - ISSN: 2177-6342 
Assim, os campos de saber não eram tão definidos como poderia parecer ou se pensar em tais momentos de transformação e redefinição do saber médico. A transformação ocorrida na prática médica e no conjunto dos saberes médicos, no fim do século XVIII e início do século XIX, na configuração do que se denominou de anatomoclínica, seguiu um curso não linear de conformação dos seus enunciados. Ao mesmo tempo, tal transformação não foi mera decorrência de descobertas científicas progressivas acerca de uma realidade objetiva, senão devido a uma mudança no olhar e na valorização de alguns discursos sobre os processos de enfermidade para produzir um saber médico compatível com as demandas sociais e políticas da época. Foi um novo recorte no vislumbre da doença, criando um olhar sobre o corpo implicado nas demandas sociais e políticas da época. Segundo Foucault (2004, p. 41, grifos do autor), nada foi muito tranquilo na configuração desse novo espaço para a prática médica, pois havia uma

[...] oposição [inicial] entre uma medicina das espécies patológicas e uma medicina do espaço social... [demandando] um fenômeno de convergência entre as exigências de ideologia política e as da tecnologia médica. Médicos e homens de Estado reclamavam em um mesmo movimento e em um vocabulário às vezes semelhante, mesmo que por motivos diferentes, a supressão de tudo o que pode ser obstáculo para a constituição deste novo espaço...

A prática médica centrada no corpo anatômico foi transformando-se posteriormente, com outros recortes, técnicas, conhecimentos nos processos de construção de seu saber, demonstrando a não linearidade da constituição dos saberes. Procurando demonstrar outros recortes que a anatomoclínica apresentou em seu desenvolvimento, ao discutir Laënnec, posterior à Bichat, Foucault (2004, p. 149) vai falar que

[...] a anatomia patológica é uma ciência que tem por objetivo o conhecimento das alterações visíveis que o estado de doença produz nos órgãos do corpo humano. A abertura de cadáveres é o meio de adquirir esse conhecimento; mas para que ele adquira uma utilidade direta... é preciso acrescentar-lhe a observação dos sintomas ou das alterações das funções que coincidem com cada espécie de alteração de órgãos.

Assim se geraram novos olhares à própria anatomoclínica, quando associada aos sintomas relacionados ao estado patológico. Do mesmo modo, acontece mais tarde, na segunda metade do século XIX, com enunciados produzidos pela pesquisa de Claude Bernard (1813-1878) que empreendeu o experimentalismo em biologia para a compreensão dos processos fisiológicos

Sapere aude - Belo Horizonte, v. 12 - n. 23, p. 128-147, Jan./Jun. 2021 - ISSN: 2177-6342 
alimentando a noção objetiva de corpo biológico. O método de Bernard, que consistia de observação-hipótese-experiência-resultado-interpretação-conclusão, constituiu-se historicamente como outro alicerce da biomedicina, apresentando uma ruptura na simples relação anatomia/sintoma para uma forma dinâmica de se observar os fenômenos da atividade dos órgãos. Pode-se afirmar que Bernard, em sua obra experimental, considera a medicina como ciência das doenças e a fisiologia como ciência da vida.

É nesse contexto histórico de afirmação da anatomoclínica como prática médica capaz de satisfazer as demandas sociais e políticas que surge, também, a homeopatia como outro saber médico. O percurso histórico dessa prática médica com relação a anatomoclínica será de embates, ora mais tensos ora menos, tornando-se, esta última, hegemônica ao ser capaz de gerar em seus saberes, os imprescindíveis e inevitáveis novos estudos populacionais de enfermidades.

Tal entendimento sobre a construção de múltiplas verdades médicas abre a possibilidade para pensarmos o saber biomédico como produto de uma época e de um conjunto de enunciados sobre o corpo que configuram categorias e organizações da doença passíveis de serem disciplinadas, nos hospitais, segundo as alterações patológicas apresentadas. Foram sendo produzidas verdades médicas que geraram efeitos de saber/poder, controlando e manipulando o corpo, em novos arranjos hospitalares, no cuidado da doença e na produção de uma nova arquitetura para o corpo, categorizando indivíduos por nomes de doenças e gerando um campo de verdades universalizantes potencialmente aplicáveis às populações, com a finalidade de recuperar o corpo e reinseri-lo nas relações de trabalho. O saber biomédico, como uma verdade sobre o corpo, se constituiu como resultante de um processo histórico. A ideia de que a verdade ou o saber sobre a doença sejam um fato inequívoco da objetividade científica já é, em si, um elemento de poder contido no âmago dessa assertiva no sentido de disciplinar os saberes produzidos ao subjugar qualquer outro conhecimento que se produza a respeito. Essa discussão nos levou a pensar sobre o que Orellana (2004, p. 334) vai dizer sobre o problema das verdades quando afirma que "[e]n efecto, no hay una verdad única y universal, pero eso no excluye la presencia material de una verdad plural y local". Portanto, o que se chama de verdade possui contextos, historicidades, descontinuidades, relatividades, sempre do ponto de vista de quem as enuncia e da posição de onde se manifesta. Dentre as correntes de pensamento médico que emergiram, naquele período, 
predominou a anatomoclínica, por se apresentar compatível com as necessidades políticas e sociais da época, sujeitando outras correntes, dentre elas a homeopatia.

No Brasil, desde o desembarque de Benoît Mure, mediante licença colonial, ocupando uma área na Península de Sahy, em Santa Catarina, fundando o Instituto Homeopático do Sahy, muitos eventos marcaram a evolução da homeopatia em nosso país. De acordo com Madel Luz (2014, p. 12),

[a homeopatia,] de saber médico marginalizado, passou à especialidade médica. De 'medicina de nossos avós', passou à terapêutica atualizada, pois integral, 'holística', respeitadora de ética das relações médico-paciente, próxima da natureza, etc. Enfim, é vista agora como uma racionalidade médica afinada com as mudanças culturais do fim do milênio passado - e início deste - e buscando ocupar seu lugar no debate atual sobre a medicina como arte de curar.

De fato, a resolução nº1000/80, reafirmada pela resolução nº1295 de 09 de junho de 1989, do Conselho Federal de Medicina reconheceu desde 1980 a Homeopatia como especialidade médica e, em 2006, por meio da Portaria Interministerial 971/2006, o Ministério da Saúde apresenta a Política Nacional de Práticas Integrativas e Complementares (PNPIC) no Sistema Único de Saúde (SUS), que atende à necessidade de se incorporar e implementar experiências esparsas já existentes na rede pública. No entanto,

as corporações ligadas à biomedicina mantêm uma hegemonia institucional fortemente embasada em argumentos 'técnicos' ou 'científicos' [...], impondo um método único de investigação para 'comprovar a cientificidade' de saberes e práticas dentro do padrão biomecânico. (LUZ, 2014, p. 13-14).

Dessa forma, permanecem, ainda hoje, marginalizadas algumas práticas médicas, a exemplo da Homeopatia, apesar dos vários movimentos que buscaram sua institucionalização. A luta pela legitimação da prática homeopática como arte médica no Brasil é constante desde 1840, sem, no entanto, conseguir transformar tal saber em campo legítimo de saberes e práticas sobre o corpo e a enfermidade.

Sapere aude - Belo Horizonte, v. 12 - n. 23, p. 128-147, Jan./Jun. 2021 - ISSN: 2177-6342 


\title{
2 HOMEOPATIA E SUAS RELAÇÕES COM O VITALISMO
}

Como mencionado acima, a Homeopatia se desenvolveu sujeitada nas relações de saber/poder imbricadas à construção dos discursos da anatomoclínica. Ao falar sobre uma das finalidades da genealogia, Foucault (2005, p. 11-12) refere à importância de se buscar instrumentos para a elaboração de projetos de investigação acerca dos saberes sujeitados:

\begin{abstract}
por 'saber sujeitado', entendo duas coisas. De uma parte quero designar, em suma, conteúdos históricos que foram sepultados... [enquanto] blocos de saberes históricos que estavam presentes... Em segundo lugar, por 'saberes sujeitados' eu entendo igualmente toda uma série de saberes que estavam desqualificados, como saberes não conceituais, como saberes insuficientemente elaborados: saberes ingênuos, saberes hierarquicamente inferiores, saberes abaixo do nível do conhecimento ou da cientificidade requeridos.
\end{abstract}

Assim, olhamos a Homeopatia, em sua história desde seus primórdios, como no Brasil, procurando chamar a atenção para a constituição de um saber médico sujeitado à biomedicina, ao mesmo tempo em que procuramos fazê-la falar.

Nesse sentido, trazemos discussões sobre a prática homeopática na qualidade de experiência médica vitalista. Ao fazer a Homeopatia falar, apresentar seus saberes e discutir possíveis ações, pretendemos trazer elementos para pensar práticas de resistência à objetividade corporal, anônima e reinante na biomedicina e que apontem tipos de cuidados no terreno de uma medicina para o sujeito e no âmbito do governo de si.

Para argumentar a hipótese vitalista da Homeopatia e sua conversão histórica em uma prática médica autônoma e legítima, inicialmente recorreremos à obra de Samuel Hahnemann, o Organon da arte de curar, por sua importância enquanto instrumento de orientação ao trabalho médico e alicerce filosófico para a prática homeopática. Essa obra fundamenta-se em princípios hipocráticos e aristotélicos em três diretrizes básicas: a primeira, no uso da vix medicatrix naturae hipocrática, que aponta a capacidade do corpo de expressar um poder que regenera a si mesmo, em que preservação e manutenção são privilegiadas, no qual a possibilidade de cura faz parte do processo e depende de decisões a se tomar sobre o regime de vida, de modo a melhor manter a ordem natural (NASCIMENTO; NOGUEIRA; BARROS; LUZ, 2013).

A segunda diretriz concerne à manifestação da alma conforme Aristóteles argumenta, em seu Peri Psyches (De Anima), na concepção de que corpo e alma se manifestam em unidade de

Sapere aude - Belo Horizonte, v. 12 - n. 23, p. 128-147, Jan./Jun. 2021 - ISSN: 2177-6342 
ação, inseparáveis ao mesmo tempo em que irredutíveis entre si, por meio de suas atividades nas sensações do ser vivo existencial.

A terceira diretriz fala sobre a concepção aristotélica de uso do corpo (chrestai, chresis), segundo o entendimento de Giorgio Agamben, ao abordar o uso do próprio corpo enquanto laboratório da vida de cada um na saúde ou na doença como um dispositivo para o entendimento da prática de cuidado de si.

\section{a) O olhar da simultaneidade do corpo}

A Homeopatia se firmou enquanto vertente vitalista alicerçada nos fundamentos das observações hipocráticas do comportamento da vix medicatrix naturae. A vix medicatrix naturae expressa um poder autorregenerador por meio do qual a conservação da saúde é dinâmica, e a possibilidade de cura depende do cuidado de si no seu modo de viver e de manter seu bem estar. Sua manifestação é observada na totalidade corporal, ou seja, na simultaneidade do conjunto dos fenômenos do corpo, tanto do ponto de vista de seu bem-estar, de seus sintomas, como de seus movimentos autorregeneradores de cura. Ou ainda, em outras palavras, em direções diferentes, tanto do adoecer como da autorregeneração, o corpo expressa seu fluxo vital na totalidade simultânea de seus eventos. Segundo Rebollo (2006, p. 55), no que tange ao fluxo da vix medicatrix naturae, cada objeto natural, e o corpo em particular, possui um comportamento de equilíbrio em sua própria dynamis enquanto objeto de observação e controle do médico hipocrático:

\footnotetext{
da totalidade do indivíduo humano, isto é, do corpo e da alma; (ii) dynamis da idade e do sexo; (iii) dynamis de cada órgão que manifesta uma atividade vital geral ou particular; (iv) dynamis das atividades e hábitos humanos; (v) dynamis dos alimentos; (vi) dynamis dos medicamentos; (vii) dynamis dos sintomas e das doenças; (viii) dynamis das estações, dos climas e das regiões.
}

Tal é o plano de simultaneidade das influências e comportamentos do corpo e do meio. Importa debater aquelas que sustentam a visão de que os sintomas da doença se mostram concomitantes, independentemente se são do físico ou da mente, e significativas das características da enfermidade. Interessante notar que a simultaneidade empírica dos sintomas já fazia parte da abordagem semiológica das práticas médicas da medicina classificatória, que antecedeu a

Sapere aude - Belo Horizonte, v. 12 - n. 23, p. 128-147, Jan./Jun. 2021 - ISSN: 2177-6342 
anatomoclínica. Por outro lado, a simultaneidade dos sintomas como totalidade sintomática é pilar semiológico e terapêutico da homeopatia. Em tal aproximação conceitual entre o materialismo da escola classificatória e o vitalismo hahnemanniano, não pretendemos afirmar que Hahnemann seguiu a escola classificatória, o que sua introdução no Organon da arte de curar deixa claro ao delimitar suas diferenças com essa escola. No entanto, procuramos mostrar possíveis correlações entre alguns elementos praticados pela medicina classificatória com alguns princípios da Homeopatia, no sentido de apontar a complexidade da formação dos saberes. As diretrizes semiológicas de Hahnemann, ao investigar a enfermidade, também emergiram como complexas rupturas, complementos e detalhamentos qualitativos aos múltiplos saberes médicos à época validados.

Historicamente, mesmo antes da emergência da Homeopatia, ao contrário da nascente anatomia patológica em que os enunciados configuraram o espaço de localização da doença no corpo orgânico, para a medicina classificatória o modo da configuração dos sintomas era diferente. Nesta, segundo Foucault (2004, p. 02), "nunca o espaço de configuração da doença foi mais livre, mais independente do seu espaço de localização". Ou ainda, para a medicina classificatória, que precedeu de perto e em muitas circunstâncias conviveu com o método anatomoclínico, “antes de ser tomada na espessura do corpo, a doença recebia uma organização hierárquica em famílias, gêneros e espécies" (p. 2); ou seja, a partir da conformação de um quadro ou um gênero de adoecimento, uma imagem de enfermidade era produzida na qual o que importava eram as condições do sujeito enfermo em suas manifestações sintomáticas simultâneas. Percebia-se a doença não em órgãos, mas em espaços de manifestação enunciáveis pela experiência dos sujeitos doentes, assim como no comportamento de história natural da evolução dos sintomas. O que importava era a observação de cada detalhe das sensações e funções alteradas, enunciadas por quem experimentava o adoecer, associada ao conjunto dos eventos distinguidos vividos como sofrimento do enfermar-se, independentemente de seu espaço de localização corporal. "A estrutura principal que a medicina classificatória se atribui é o espaço plano do perpétuo simultâneo." (FOUCAULT, 2004, p. 05).

O estudo de cada caso, na medicina classificatória, apesar de materialista, era efetuado com base na manifestação espontânea dos sintomas na ordem da experiência do sujeito e de como os sintomas evoluíam no viver do paciente enquanto "um decalque do mundo da vida [...] reconhece-

Sapere aude - Belo Horizonte, v. 12 - n. 23, p. 128-147, Jan./Jun. 2021 - ISSN: 2177-6342 
se a vida na doença, visto que é a lei de vida que, além disso, funda o conhecimento da doença" (FOUCAULT, 2004, p. 6). Ele acrescenta que, na técnica da medicina classificatória,

a principal perturbação é trazida pelo próprio doente [...] [que] acrescenta como perturbação sua disposição, sua idade, seu modo de vida e toda uma série de acontecimentos que figuram como acidentes em relação ao núcleo essencial, [em que] não é o patológico que funciona com relação à vida, como uma contranatureza, mas o doente com relação à própria doença. (FOUCAULT, 2004, p. 07).

Nesse sentido, as enfermidades se configuravam na observação pura e simples dos fenômenos do corpo em adoecimento - à semelhança do que notava nos seus processos de regeneração - manifestando-se na totalidade narrada do sentir, fundamentadas no acompanhamento de sua evolução natural, ou seja, no "seguir passo a passo os caminhos que toma a natureza [...]; [ou seja] a doença nele só existe na medida em que ele a constitui como natureza" (FOUCAULT, 2004, p. 08), pilar hipocrático de observação.

Outra característica do olhar da medicina classificatória para os processos de enfermidade vem a ser que "o fato de atingir um órgão não é absolutamente necessário para definir uma doença, esta pode ir de um ponto a outro de localização, ganhar outras superfícies corporais, permanecendo idêntica em sua natureza" (FOUCAULT, 2004, p. 09). Nesse caso, importa a sincronicidade dos eventos experimentados pelo sujeito como doença, os fluxos de sua manifestação, a experiência do adoecer, a imbricação dos múltiplos sintomas e o amalgamento e interfaces da experiência percebida pelo sujeito nas relações com o meio em que vive. Além disso, pode-se inferir do que nos diz Foucault acima, que a definição de doença também poderia, ao não ser imprescindível sua localização em um órgão, encontrar espaço de validação na legitimidade das sensações e funções alteradas percebidas e narradas pelo sujeito que adoece. Para se entender algum processo de enfermidade vivido pelo sujeito, o central seria ouvir, então, o que teria a dizer o paciente. Para a medicina classificatória, conforme Foucault (2004, p. 12),

O que faz o ‘corpo' essencial da doença [na medicina classificatória] não são, portanto, os pontos de localização [...] é antes de tudo a qualidade [dos sintomas vividos] [...] a doença e o corpo só se comunicam por intermédio do elemento não especial da qualidade [dos sintomas].

Sapere aude - Belo Horizonte, v. 12 - n. 23, p. 128-147, Jan./Jun. 2021 - ISSN: 2177-6342 
Essa maneira de se ver a enfermidade levou-nos a perceber uma inusitada e heterogênea intersecção entre a medicina classificatória e a Homeopatia, pois, para ambas, é crucial, na aproximação do entendimento da doença, o processo de singularização qualitativa da história de adoecimento. A esse respeito, Hahnemann (1996, p. 80, grifo do autor) irá escrever, no parágrafo 18 , que

não há, de modo algum, nas doenças, salvo a totalidade dos sintomas e suas modalidades, nada que possa ser encontrado e que expresse a necessidade de intervenção do auxílio à doença, [e] depreende-se, inegavelmente, que a essência de todos os sintomas percebidos e das circunstâncias em cada caso individual de doença é a única indicação, o único denotador do meio de cura a ser escolhido.

Para Hahnemann (1996, p. 144), a investigação semiológica buscando a singularidade qualitativa da enfermidade assim se apresenta:

Uma vez registrada de modo preciso a totalidade dos sintomas que caracterizam e distinguem especialmente o caso de doença, [...] está concluída a parte mais difícil do trabalho. $\mathrm{O}$ artista da cura tem, então, a imagem da doença sempre diante de si durante o tratamento.

Importa salientar que tal imagem se produz através das narrativas do doente e não de imagens corporais de sua anatomia orgânica propriamente dita. São autoimagens de como o sujeito se percebe enfermo, em suas próprias sensações, conexões, impressões, para além de nomes de patologias. Com esse tipo de narrativa, apresenta-se uma visão da experiência ampliada que não se relaciona a um mero acúmulo de informações acerca de uma realidade objetiva. Trata-se de um experimentar humano em seu viver como "a possibilidade de que algo nos aconteça ou nos toque" (LARROSA, 2002, p. 24), nos alcance e que se apodere de nós, que nos tomba e nos transforma.

Dessa perspectiva, a entrevista homeopática para compreender a enfermidade se caracteriza por ser minuciosa na busca da qualidade dos sintomas e sensações alteradas. Nela torna-se central perceber o doente no seu viver relacional consigo, com os outros e com o meio. A concomitância sintomática é, na maior parte das vezes, mais significativa para a compreensão do sofrimento do que a localização orgânica da patologia. Esse cenário permitiu a Hahnemann conceituar a enfermidade como uma totalidade sintomática e existencial, um evento único e singular na experiência do sujeito que adoece, pois, nesse contexto a simultaneidade de intensidades como a

Sapere aude - Belo Horizonte, v. 12 - n. 23, p. 128-147, Jan./Jun. 2021 - ISSN: 2177-6342 
tristeza, o medo e outras afecções da mente com o que se sente fisicamente, dores ou disfunções físicas, se tornam uma única experiência narrada de enfermidade.

Nesse sentido, procuramos argumentar que seja possível dizer que o vitalismo da medicina de Hahnemann apresentava, historicamente, intersecções com certos conceitos da medicina classificatória acerca da enfermidade, mesmo divergindo dos seus princípios materialistas, do mesmo modo que também se mostra alicerçada em princípios vitalistas aristotélicos propriamente ditos para estruturar sua concepção: é o que veremos adiante.

\section{b) $\mathbf{O}$ vitalismo hanemanniano e Aristóteles: a unidade mente/corpo}

Para tal discussão iniciaremos apresentando como Hahnemann (1996, p. 73) descreve em seu livro Organon da arte de curar a manifestação da Força Vital (FV):

[§9] No estado de saúde do indivíduo reina, de modo absoluto, a força vital de tipo não material, que anima o corpo material como 'Dynamis', mantendo todas suas partes em processo vital admiravelmente harmônico nas suas sensações e funções (p. 73).

[§10] O organismo material, pensado sem a força vital, não é capaz de qualquer sensação, qualquer atividade, nem de autoconservação (p. 73-74).

[§11] Quando o homem adoece é somente porque, originalmente, esta força de tipo não material presente em todo organismo, essa força vital de atividade própria foi afetada... levando-o a funções irregulares a que damos o nome de doença (p. 74).

[§12] Somente a força vital afetada produz as doenças, de modo que ela se exprime no fenômeno mórbido perceptível aos nossos sentidos, simultaneamente... revelando toda a doença” (p. 77).

É possível ver que Hahnemann argumenta que somente tal força imaterial poderia conferir a possibilidade de sensações que, quando afetadas por fatores de desequilíbrio, seriam os sintomas da enfermidade. Tais sensações seriam o modo como o corpo age durante a enfermidade, a totalidade da ação do corpo na doença e suas manifestações ao exibir sua forma na dinâmica vital do sujeito, de como surgiram em seu viver nas suas relações estabelecidas e de como as sofreu. Nada do que ocorre nas dinâmicas da força vital seria separado do corpo vivo e das percepções e sensações do sujeito doente. Dessa forma, abre-se a possibilidade para um entendimento da doença e seu processo terapêutico como parte do movimento existencial do sujeito.

Sapere aude - Belo Horizonte, v. 12 - n. 23, p. 128-147, Jan./Jun. 2021 - ISSN: 2177-6342 
Propomos que sua inspiração tenha relações com a noção aristotélica de alma e de dynamis. Aristóteles, em De anima, afirma que não há como definir alma enquanto princípio vital meramente incorpóreo que anima o corpo e que seja independente dele. Ao contrário, argumenta da seguinte forma: "A alma não parece ser afetada nem pode produzir qualquer afecção sem o corpo." (ARISTÓTELES, 2010, p. 403 a5). Afirma, ainda, que "a alma é uma substância de acordo com uma definição, e isso é o que é ser para um corpo" (ARISTÓTELES, 2010, p. 421 b10) ao mesmo tempo em que afirma que ser é ato, ação de ser, “a matéria é, por sua vez, potência, ao passo que sua forma é ato" (ARISTÓTELES, 2010, p. 412 a10), buscando correlacionar atividade/ação. Ser, ato e forma seriam, para Aristóteles, atribuições da alma. Dynamis, como potência de ser e o princípio vital como forma, ato e alma enquanto "ser para o corpo", fazem parte de um conjunto conceitual aristotélico. O corpo aparece aqui como potência (dynamis) para manifestação da alma, como princípio vital, na forma de atitudes, conduta, movimento corpóreo. Para o filósofo grego, a manifestação da alma acontece nas ações de um corpo sensível que manifesta a experiência no ser e fazer ao exemplificar que o olfato somente traz sentido quando percebido como cheiro na experiência da alma. Se audição, visão, olfato e tato se referem ao corpo, ver, ouvir, cheirar e tocar se referem à experiência, ao agir e, portanto, à alma. Os estudos desses princípios aristotélicos permitem pensar que foram nessas experiências de sensações e de sentir que Hahnemann alicerçou suas percepções de enfermidade como dynamis. Às alterações do olfato, como se veria na biomedicina, na homeopatia voltaríamos a atenção para os cheiros percebidos como significantes do processo de adoecimento. Assim, enfermidade para Hahnemann seria efeito da alteração dinâmica de uma Força Vital ao se manifestar no ser que agiria sempre simultaneamente e em uníssono, tanto a estrutura corporal como a experiência de ser do corpo como efeitos da psykhê. Ao examinarmos a obra de Hahnemann (1996, p. 194-195, grifo do autor) torna-se visível tal unidade existencial entre mente e corpo:

as chamadas doenças psíquicas e mentais [...] não constituem, porém, uma classe nitidamente isolada de todas as outras, pois em todas as demais, as assim chamadas doenças físicas, a disposição psíquica e mental está sempre se modificando e, em todos os casos de doença que devem ser curados, o estado psíquico deve concorrer como um dos mais notáveis no conjunto característico dos sintomas.

Sapere aude - Belo Horizonte, v. 12 - n. 23, p. 128-147, Jan./Jun. 2021 - ISSN: 2177-6342 
Ou seja, se para Aristóteles a alma é movimento, para Hahnemann o corpo não "pensado sem a força vital, [pois assim] não é capaz de qualquer sensação" (HAHNEMANN, 1996, p. 73) e sensação é movimento e intensidade, percepção psíquica de si. O processo de adoecer, ao modificar o devir existencial, conforme o vitalismo hanemanniano, apresenta-se como alteração da FV, na qual os eventos psíquicos são manifestações fundamentais e características. Assim, se estabelece intensa articulação entre Força Vital, dynamis, sensações, atividade e enfermidade, mente e corpo. Enfermidade seria um evento heterogêneo e de múltiplas articulações que perturbaria a totalidade existencial do indivíduo no modo como ele se conhece e subjetiva seu adoecer, como enuncia seu sofrer, não importando a localização orgânica da patologia. Não há como adoecer do corpo sem que sejam registrados os sofrimentos emocionais concomitantes. Para Hahnemann (1996, p. 135136), seria no psíquico onde se manifestariam os mais característicos e singulares eventos representantes da suscetibilidade do doente. Ele propõe ser crucial na compreensão da enfermidade estudar a "disposição psíquica e as condições psíquicas e mentais do doente"; se houve fatos que perturbaram o sujeito tais como "amores infelizes, ciúme, infelicidade, preocupações, tristeza, maus tratos, vingança, frustração, orgulho ferido, problemas econômicos, medos, fome... e suas habituais ocupações, modo de vida, dieta, situação doméstica" (HAHNEMANN, 1996, p. 139). Seria no âmbito de corpo e dynamis que Hahnemann fundamentaria seu conceito de força vital no aristotelismo para poder afirmar a unidade inseparável do corpo e da mente e, assim, estabelecer uma semiologia específica de investigação da enfermidade singular. A percepção de si e o uso que faz de seu corpo, na história clínica homeopática, é essencial para a compreensão do cuidado que deve ser tomado a respeito de si.

\section{c) O que seria o uso do corpo?}

As possíveis conexões entre Hahnemann e Aristóteles não se limitam ao entendimento das relações entre mente e corpo, mas também ao que Aristóteles chamava de "uso do corpo". Agamben (2017, p. 83-84) argumenta que:

a relação entre ser e ter [entre alma e corpo] é, na verdade, mais íntima e complexa. A hexis, a potência enquanto hábito... indica o estado do ser como atribuído a um sujeito. $\mathrm{O}$ que se tem na hexis é certo modo de ser... Esse ser-que-se-tem é chamado por Aristóteles

Sapere aude - Belo Horizonte, v. 12 - n. 23, p. 128-147, Jan./Jun. 2021 - ISSN: 2177-6342 
de dynamis, potência e dynatos, potente, é quem tem aquele determinado estado e aquele determinado ser... é 'ter um ser'.

Para o entendimento de Agamben, "ter" um corpo e "ser” sujeito de alma livre, o uso do corpo e da alma, era uma questão importante para Aristóteles, traduzido na polissemia do verbo chrestai. O objetivo dos sujeitos na antiga Grécia era buscar a disponibilidade de sua alma para seu livre pensar sobre suas condições de cidadão. Definia-se que o corpo escravo, como posse do senhor, era parte do próprio corpo do senhor, que o utilizava publicamente nas construções da comunidade e obras sociais, deixando o cidadão de alma livre para viver e pensar com seus semelhantes na pólis. "Colocando em uso o próprio corpo, o escravo é, por isso mesmo, usado pelo senhor, e, ao usar o corpo do escravo, o senhor na realidade usa o próprio corpo" (AGAMBEN, 2017, p. 32), ficando livre para o pensar e para o cuidado de si: tal é a polissemia do verbo chrestai, como uso do corpo.

Segundo Agamben (2017, p. 46), o conceito do verbo chrestai remete a uma ação em que o sujeito "realiza algo que se realiza nele", ou ainda, "o sujeito que realiza a ação, pelo fato mesmo de realizá-la, não age transitivamente sobre um objeto, mas implica e afeta, sobretudo, a si mesmo no processo [...] o sujeito não ultrapassa a ação, mas é ele mesmo o lugar de seu acontecer" (AGAMBEN, 2017, p. 47). Agamben define o verbo chrestai como uso do corpo em uma ação que se realiza sobre si, já não se refere mais ao uso do escravo, mas ao uso do próprio corpo do sujeito existencial. Tal ação pode ter efeitos sobre o indivíduo: em que a ação é de submissão à verdade do outro na conservação das relações de poder ou que a ação sobre si produz uma resistência à verdade do outro, alicerçando outras formas de liberdade. Por exemplo, em uma consulta médica, pode-se tratar de uma situação em que o paciente, ao invés de se submeter à verdade do discurso biomédico, pode compreender o uso que fez de si no transcurso da emergência da enfermidade que o faz sofrer e pode criar novas relações e resistências no governo de sua vida no sentido de seu bem-estar. Pensamos que a Homeopatia pode contribuir nesse sentido. Para ela, a enfermidade emerge como experiência ou experimentação de acontecimentos vitais, no uso que o paciente fez de si, em seus momentos existenciais, ao não resolver situações perturbadoras de sua vida, submetendo-se assim a situações existenciais que o tornam acorrentado ao seu sofrer e mobilizando, em seu corpo, funções e sensações significantes, modelando sua enfermidade.

Sapere aude - Belo Horizonte, v. 12 - n. 23, p. 128-147, Jan./Jun. 2021 - ISSN: 2177-6342 
Seria nesse contexto que procuraríamos entender o adoecimento como experiência, como modo de constituir hábitos e estar predisposto, conforme é atravessado pelos agenciamentos produzidos no seu viver. Segundo Agamben (2017, p. 49), tal experiência "é antes de tudo o uso de si: para entrar em relação de uso com algo, eu devo ser afetado, constituir a mim mesmo como aquele que faz uso de si”, seja na compreensão de seu adoecer como na perspectiva de poder se libertar. Ele argumenta, ainda que "o sujeito não é substância, mas processo, ... a dimensão ética o cuidado de si - [também] não tem substância autônoma: não tem outro lugar nem outra consistência senão a relação de uso entre o homem e o mundo. O cuidado de si pressupõe a "chresis"” (AGAMBEN, 2017, p. 53), fazendo de si e de seu próprio corpo o lugar do acontecimento de seu devir, seja em saúde ou em enfermidade. "A relação consigo mesmo tem, portanto, constitutivamente a forma de uma criação de si, e não há outro sujeito senão nesse processo.” (AGAMBEN, 2017, p. 127).

Propomos que, para a homeopatia, o entendimento exposto por Agamben do verbo chrestai pode guardar relação com o uso que se tem de si durante a vida, a partir dos efeitos e sensações percebidas como enfermidade, na modificação das funções prévias (exacerbação, diminuição, intensidades), no surgimento de sensações e funções nunca antes sentidas. A narrativa fiel, pessoal e verdadeira das sensações e funções alteradas percebidas em si seriam os elementos semiológicos para o entendimento da enfermidade dinâmica e singular em homeopatia. Fazemos uso constante e permanente de nosso corpo, que se manifesta em experiências vitais sentidas e narradas por nossa percepção de como nos inserimos e sofremos em nossa existência. Esse "uso" significa um fazer sobre si mesmo, e é nele que encontramos a semente da transformação, possibilitando outra disposição, outra relação com o viver, para assim poder ressignificar o modo de vida que o adoeceu.

É importante salientar, nesse cenário, o papel central que tem a palavra e o linguajar do sujeito na entrevista homeopática. Todo o processo de auto-observação definirá seu modo de perceber a si mesmo, a descrição exclusivamente por meio das palavras daquele que experimenta a enfermidade, no modo como sente e fala, na singularidade do que percebe de alterado em suas sensações e funções no seu viver cotidiano. A palavra e o ato linguajante do doente serão as balizas para a potência e intensidade manifestas no corpo vital subjetivado.

Essa condição de falar de si como parâmetro do bem-viver relaciona-se com os escritos de Orellana. Ao discutir os jogos de verdade que aparecem nos últimos escritos de Foucault, por meio

Sapere aude - Belo Horizonte, v. 12 - n. 23, p. 128-147, Jan./Jun. 2021 - ISSN: 2177-6342 
dos quais o ser se constitui historicamente como experiência, e trata a respeito da temática da parrhesia, ele afirma:

parrhesia significa 'decirlo todo'. 'hablar libremente', ejercer una 'libertad de palabra'. Esta capacidad involucra una mezcla de destreza, virtud, obligación y técnica que el individuo pone en practica con el propósito de orientar el trabajo del cuidado de si que otro compañero desarrolla... en la construcción artística de la propia vida. (ORELLANA, 2004, p. 337).

O paciente precisa abrir um espaço em sua vida para auto-observação para, enfim, ver a si mesmo e poder narrar-se em sua própria linguagem; ver a si mesmo como ser histórico, vivido, particular e singular, consequência do efeito de suas experiências no uso que faz de si e, assim, capacitado no sentido da construção de um governo de si.

Para Larrosa (2002, p. 24), assim se configura

[o] sujeito da experiência [...] não o sujeito do saber, do julgar, do fazer, do poder [...] o sujeito da experiência seria algo como um território de passagem, algo como uma superfície sensível que aquilo que acontece afeta de algum modo, produz alguns afetos, inscreve algumas marcas, deixa alguns vestígios, alguns efeitos [...] é um ponto de chegada [não predeterminado], o sujeito da experiência é sobretudo um espaço onde tem lugar os acontecimentos.

\title{
3 UMA MEDICINA PARA O GOVERNO DE SI
}

Conforme Portocarrero (2009, p. 227), a partir dos anos 1970, Foucault

\begin{abstract}
elabora uma genealogia da ética que é uma estética da existência, uma pesquisa da maneira pela qual os indivíduos buscam formar, pelo meio de escolhas pessoais, modos de vida, 'ethos de liberdade', em que a própria vida humana é um trabalho, uma obra de arte... [através] de uma análise do modo pelo qual os homens se governam a si mesmos e aos outros através da produção da verdade.
\end{abstract}

O governo de si pode ser "definido como conjunto de experiências modificadoras do sujeito para ter acesso à verdade com a finalidade de transformar o ser mesmo do sujeito" (PORTOCARRERO, 2009, p. 235). Em sua fase tardia, Foucault propôs a retomada das relações de si para consigo, nos contextos dos jogos de poder em que se insere, como fonte de resistência e 
possível transformação, problematizando "a autoformação do sujeito... [centralizada] na ideia de constituição de si mesmo como experiência.” (PORTOCARRERO, 2009, p. 237).

Dessa perspectiva, procuramos trazer elementos para pensar uma prática médica articulada a um tipo de vitalismo da percepção de si enunciada por meio do discurso de si e do narrar a si nos movimentos existenciais dos indivíduos. Assim, poder-se-ia praticar a homeopatia, criando condições para o sujeito perceber seu corpo em torno de seus fluxos existenciais, inserido em ontologias modais de suas práticas vitais diárias. Práticas geradas e contextualizadas nos desafios impostos pelos efeitos de poder/saber, nas relações entre médico e paciente, nas relações familiares e do trabalho e, em especial, nas relações que o sujeito tem consigo mesmo, atravessado por suas experiências existenciais. Discutimos a possibilidade de construção de práticas de liberdade voltadas ao sujeito.

Para o médico homeopata, é no narrar de si que caminhamos ao encontro da percepção de si. Nesse sentido, as configurações corporais e subjetivas de cada um são sempre históricas, múltiplas e processuais, estabelecidas nos espaços de interação das pessoas, em que elas experimentam a vida, imersas em modos e formas linguajantes. O indivíduo corporificado "nunca cessa de nascer" (AGAMBEN, 2017, p. 200). Suas histórias de vida são sempre "uma leitura e uma releitura ao longo do tempo. Ela nunca é uma verdade, apenas a última versão que um indivíduo oferece de si mesmo" (AGAMBEN, 2017, p. 202). Não há doença estabelecida, simplesmente, há processos de adoecimento.

Enfim, trata-se de voltar as costas ao esvaziamento ontológico existencial característico das práticas biomédicas, que usam o corpo no sentido de sua disciplinarização e ordenamento, em patologias praticamente autônomas e impessoais, para lutar por uma ontologia modal da subjetividade corporificada, singular e percebida nas contingências da potência vital de cada um.

\section{CONSIDERAÇÕES FINAIS}

Procuramos trazer outro olhar para as práticas médicas. A partir de uma perspectiva histórica da construção dos saberes, identificamos aqueles que são hegemônicos e outros que são sujeitados. Ao escrutinar a história das relações de saber e poder na constituição dos discursos médicos, nós buscamos fazer falar um tipo de saber médico que consideramos "sujeitado" devido

Sapere aude - Belo Horizonte, v. 12 - n. 23, p. 128-147, Jan./Jun. 2021 - ISSN: 2177-6342 
às demandas sociais e políticas de onde se originaram as práticas ora vigentes até a contemporaneidade: da anatomoclínica à biomedicina. Discutimos, então, sobre outro saber médico que orienta outro espaço de compreensão para a prática médica, capaz de ser centrada no cuidado do sujeito e orientada para um trabalho do governo de si. Assim, vemos as possibilidades da homeopatia e de suas compreensões de enfermidade.

Ao debater outro olhar sobre a enfermidade, percebemos os movimentos de corpos subjetivados vivendo seu viver, sentindo seus processos existenciais e experimentando seus fluxos, seja permitindo-os ou cristalizando-os, proporcionando bem-estar ou mal-estar. Um corpo vivido pelo sujeito, que incorpora seu existir ao pensar sobre si e falar sobre si. Somos constantes mutações nos modos e formas de viver essa vida que se conserva em nós. Se assim for, em um cuidado legítimo e ético de si, tende-se a viver em sentido de bem viver, pois sujeitos configuram a si mesmos em espaços psíquicos maleáveis, vividos no interior de relações sociais. A enfermidade torna-se um processo imbricado ao fluxo da experiência.

Dessa perspectiva, a homeopatia pode ser vista como uma prática de se fazer medicina centrada no falante, em que o dizer a verdade profunda de seu sofrer traduz a verdade própria do doente. Um sujeito que se forja em sua corporeidade na trajetória existencial singular, na interconexão de suas experiências históricas, emocionais, existenciais e relacionais, na família, no trabalho etc., produto de efeitos das relações em que se subjetivou e reagiu. Uma abordagem e escuta da enfermidade, ética com o autoconhecimento e constituída enquanto valores existenciais ligados ao cuidado de si.

\section{REFERÊNCIAS}

AGAMBEN, Giorgio. O uso dos corpos [Homo sacer, IV, 2]. São Paulo: Boitempo, 2017.

ARISTÓTELES. Sobre a alma. Imprensa Nacional - Casa da Moeda, 2010.

CANGUILHEM, Georges. O conhecimento da vida. Rio de Janeiro: Forense Universitária, 2012.

FOUCAULT Michel. Em defesa da sociedade. São Paulo: Martins Fontes, 2005.

FOUCAULT, Michel. O nascimento da clínica. Rio de Janeiro: Forense Universitária, 2004.

HAHNEMANN, Samuel. Organon da arte de curar. São Paulo: Robe Editorial, 1996.

Sapere aude - Belo Horizonte, v. 12 - n. 23, p. 128-147, Jan./Jun. 2021 - ISSN: 2177-6342 
LARROSA, Jorge Bondia. Notas sobre a experiência e o saber de experiência. Revista Brasileira de Educação. n 19, p 20-28, 2002.

LUZ, Madel Theresinha. A arte de curar versus a ciência das doenças: a história social da homeopatia no Brasil. Porto Alegre: Rede Unida, 2014.

NASCIMENTO, Marilene; NOGUEIRA, Maria Inês; BARROS, Nelson; LUZ, Madel. A categoria racionalidade médica e uma nova epistemologia em saúde. Rev. Ciência e Saúde Coletiva, Rio de Janeiro, v. 18, n 12, 2013.

ORELLANA, Rodrigo Castro. Ética para un rostro de arena: Michel Foucault y el cuidado de la libertad. Madrid: Universidad Complutense de Madrid - Faculdad de Filosofía - Tese de doutorado, 2004.

PORTOCARRERO, Vera. As ciências da vida: de Canguilhem a Foucault. Rio de Janeiro: FIOCRUZ, 2009.

REBOLLO, Regina Andrés. O legado hipocrático e sua fortuna no período greco-romano: de Cós a Galeno. SCIENTILE Studia, São Paulo, v. 4, p. 45-82, 2006. 